\title{
Study of Effect of Shavasana on Handgrip and Cold Pressor Test on Heart Rate and Blood Pressure in Young Adults
}

\author{
Sandip R. Sardessai ${ }^{1}$, Sanjay S. Pandarbale ${ }^{2}$ \\ ${ }^{1}$ Department of Physiology, Goa Medical College, Bambolim, Goa, India. \\ ${ }^{2}$ Department of Physiology, Goa Medical College, Bambolim, Goa, India.
}

\section{ABSTRACT}

\section{BACKGROUND}

Shavasana or a corpse pose is the final pose of a yoga flow. When practiced regularly it is known to restore the body and mind. Aim of our present study was to investigate the effects of shavasana on handgrip and cold pressor test on heart rate and blood pressure in apparently healthy young adults. In today's world all of us are under constant stress and majority of individuals with sedentary lifestyle suffer from hypertension and each of us react differently to varied internal and external stimuli.

\section{METHODS}

For convenience, we took 300 apparently healthy medical students of both sexes in the age group of 18 to 22 years and a comparative study was carried out among them. Their basal pulse and BP were recorded from dominant hand. For Hand Grip Test (HGT) handgrip dynamometer (INCO) was used by left hand, and pulse and BP from right hand was recorded and similarly Cold Pressor Test (CPT) was carried out by immersing left hand up to wrist joint in cold water mixed with ice cubes to maintain temperature at $4^{\circ} \mathrm{C}$ and pulse and $\mathrm{BP}$ was recorded from right hand. Shavasana was performed for 15 minutes by lying down on the wooden couch, with eyes closed and lying on back, keeping arms six inches away from the body and legs and feet "drop" open and palms facing upwards and concentrating on their breathing, after which pulse and BP was recorded. This was carried out for a period of 30 days.

\section{RESULTS}

Data was collected and analysed using paired ' $\mathrm{t}$ ' test and paired differences were calculated using 95\% confidence interval of the difference and $p$ value of $<0.05$ was taken as scientifically significant. In our study we found that there is significant decrease in basal pulse rate, when compared with CPT, immediately and after performing shavasana for a period of one month, and there was significant increase in pulse rate following HGT ( $\mathrm{p}<0.001$ ) (table 1 and graph 1 ). Compared to basal, SBP and DBP, it was observed that there is significant decrease; immediately and after performing shavasana for one month and significant increase with HGT and CPT was observed $(\mathrm{p}<0.001)$ (table 1 and graph 1 ).

\section{CONCLUSIONS}

There is a significant decrease in basal pulse rate, when compared with CPT, immediately and after performing shavasana for a period of one month, and there was significant increase in pulse rate following HGT $(\mathrm{p}<0.001)$ (table 1 and graph 1). Compared to basal, SBP and DBP it was observed that there is significant decrease; immediately and after performing shavasana for one month and significant increase with HGT and CPT was observed ( $\mathrm{p}<0.001$ ) (table 1 and graph 1).

\section{KEY WORDS}

HGT, CPT, Shavasana, Hand Immersion in Cold Water at $4^{\circ} \mathrm{C}, \mathrm{SBP}, \mathrm{DBP}$.
Corresponding Author: Dr. Sandip R. Sardessai, Professor and HOD, Department of Physiology, Goa Medical College, Bambolim, Goa, India. E-mail: dr.sandipsardessai@yahoo.com

\section{DOI: $10.14260 / j e m d s / 2020 / 323$}

Financial or Other Competing Interests: None.

How to Cite This Article: Sardessai SR, Pandarbale SS. Study of effect of shavasana on handgrip and cold pressor test on heart rate and blood pressure in young adults. J. Evolution Med. Dent. Sci. 2020;9(18):1480-1483, DOI: 10.14260/jemds/2020/323

Submission 21-02-2020, Peer Review 17-04-2020, Acceptance 23-04-2020, Published 04-05-2020.

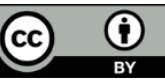




\section{BACKGROUND}

In today's world all of us are under constant stress and majority of individuals with sedentary lifestyle suffer from hypertension and each of us react differently to varied internal and external stimuli. Stress caused due to varied factors can affect cardiovascular system. ${ }^{1}$ Shavasana or a corpse pose is the final pose of a yoga flow. It is not like taking a nap, but is a fully conscious pose aimed at being awake, yet completely relaxed. Shavasana is a yogic technique which causes relaxation and it is beneficial to fight against stress. Shavasana is relaxation form of yoga which is known to reduce pulse and blood pressure. If we inculcate this habit in our life it can help in preventing stress related cardiovascular complications. ${ }^{2}$ When practiced regularly it is known to restore the body and mind. ${ }^{3}$ Majority of individuals with essential hypertension and some with usually normal blood pressure manifest unusual lability and marked reaction of blood pressure to various internal and external stimuli. This suggests that mechanism for regulating blood pressure possessed by in these individuals is hyper reactive. Some authors consider cold pressor test (CPT) as satisfactory method of determining the reactivity of blood Pressure to external stimulus and suggest its use as clinical test for predicting susceptibility of an individual to hypertension. ${ }^{4}$ Also some consider hand grip test as a good method of determining reactivity of blood pressure to external stimuli. ${ }^{5}$ Present study was therefore undertaken to study effects of shavasana on cold pressor test and hand grip in normal Subjects.

\section{METHODS}

The present study was conducted using before and after experimental study /interventional study design. ${ }^{6}$ Consisting of measurements at Basal, HGT, CPT, immediately after performing shavasana for 15 minutes and after performing shavasana for 15 minutes daily for a period of one month Informed consent was taken, and procedure was carried out. Subjects basal pulse rate and blood pressure were recorded and after this they were informed to use Handgrip dynamometer (INCO) by left hand and pulse rate and blood pressure was recorded from right hand.

After attaining basal pulse rate and blood pressure, cold pressor test (CPT) was performed by immersing subjects left hand up to wrist joint in cold water mixed with ice cubes to maintain temperature at $4^{\circ} \mathrm{C}$ for 30 seconds which was kept in thermocol box. ${ }^{4}$ Pulse rate and blood pressure was recorded from right hand. Shavasana was performed for 15 minutes by lying down on the wooden couch, with eyes closed and lying on back, keeping arms six inches away from the body and legs and feet "drop" open and palms facing upwards and concentrating on their breathing, It's a peaceful act and doesn't demand any physical exertion. ${ }^{7}$ Immediately after which subjects pulse rate and BP was recorded. Subjects performed shavasana 15 minutes every day for 30 days and at the end of which subjects, Pulse rate and BP were recorded under 3 conditions, basal, following HGT, and CPT.

\section{Inclusion Criteria}

Subjects were kept three hours postprandial and rested for half an hour before recording basal pulse rate and blood pressure.

\section{Exclusion Criteria}

Subjects who performed regular exercise, pranayama, on medications like antihypertensive, sedatives, analgesics or alcohol Consumption 24 hours before the commencement of test and those not willing to participate.

\section{RESULTS}

Data was collected and analysed using paired ' $\mathrm{t}$ ' test and paired differences were calculated using 95\% confidence interval of the difference and $p$ value of $<0.05$ was taken as scientifically significant. In our study we found that there is significant decrease in basal pulse rate, when compared with CPT, immediately and after performing shavasana for a period of one month, and there was significant increase in pulse rate following HGT $(\mathrm{p}<0.001)$ (table 1 and graph 1 ). Compared to basal, SBP and DBP both it was observed that there is significant decrease, immediately and after performing shavasana for one month and significant increase with HGT and CPT was observed $(\mathrm{p}<0.001)$ (table 1 and graph 1).

\begin{tabular}{|ccccc|}
\hline $\begin{array}{c}\text { Parameters (n=300) } \\
\text { Pulse Beats min. }\end{array}$ & Mean \pm SD & T & df & P Value \\
Basal & $78.03 \pm 2.018$ & & & \\
HGT & $82.13 \pm 1.342$ & 51.128 & 299 & .001 \\
CPT & $76.37 \pm 2.888$ & & 299 & .001 \\
Immediately after shavasana & $75.08 \pm 1.342$ & 23.154 & 299 & .001 \\
One month after shavasana & $69.88 \pm 2.018$ & 50.565 & 299 & .001 \\
SBP mmHg & & & & \\
Basal & $114.71 \pm 2.018$ & & 299 & .001 \\
HGT & $130.01 \pm 2.839$ & 56.455 & 299 & .001 \\
CPT & $128.61 \pm 1.850$ & 43.954 & 299 & .001 \\
Immediately after shavasana & $105.99 \pm 5.027$ & 32.546 & 299 & .001 \\
One month after shavasana & $103.11 \pm 4.800$ & 53.552 & 299 & .001 \\
DBP mmHg & & & & \\
Basal & $73.91 \pm 2.888$ & & 299 & .001 \\
HGT & $87.26 \pm 1.342$ & 15.892 & 299 & .001 \\
CPT & $89.24 \pm 3.267$ & 70.757 & 299 & .001 \\
Immediately after shavasana & $69.11 \pm 2.018$ & 32.546 & 299 & .001 \\
One month after shavasana & $68.89 \pm 2.138$ & 16.379 & 299 & .001 \\
\hline Table 1. Showing Effects of HGT and CPT on Pulse and BP Immediately \\
and after Performing Shavasana Daily for One Month Expressed as \\
Mean \pm SEM. Paired $\boldsymbol{t}$ Test with and Paired Differences were Calculated \\
$\quad$ Using 95\% Confidence Interval of the Difference \\
\hline
\end{tabular}

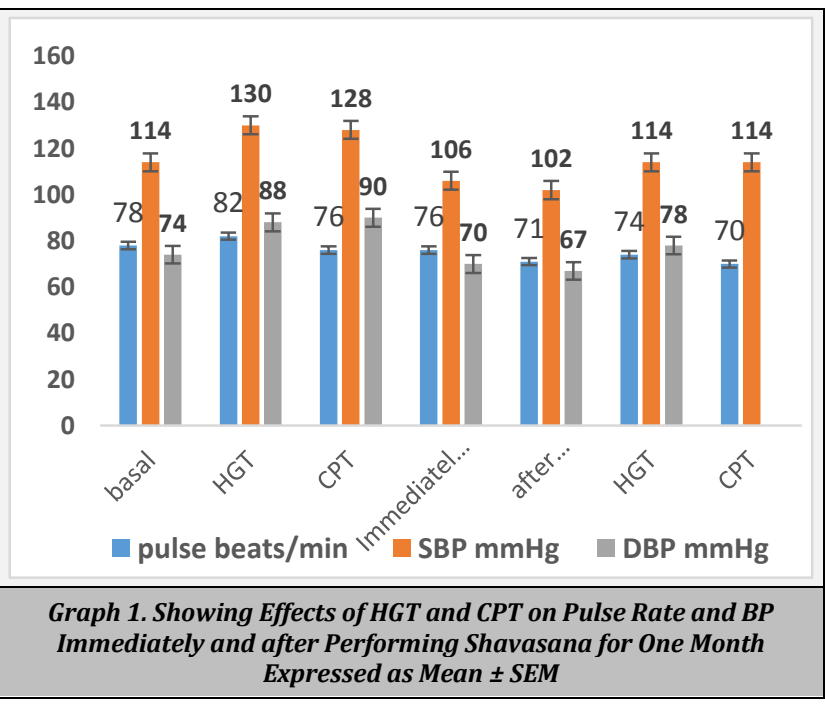




\section{DISCUSSION}

The aim of our study was to see effects of shavasana on HGT and CPT in overall young apparently healthy individuals in the age group of 18-22 years. In our study we found that there is significant decrease in basal pulse rate, when compared with CPT, immediately and after performing shavasana for a period of one month, and there was significant increase in pulse rate following HGT $(\mathrm{p}<0.001)$ (table 1 and graph 1). Compared to basal, SBP and DBP both it was observed that there is significant decrease, immediately and after performing shavasana for one month and significant increase following HGT and CPT was observed ( $\mathrm{p}<0.001$ ) (table 1 and graph 1 ).This is because while doing HGT with hand grip power dynamometer there is isometric contraction plus it's a stressful exercise. So, both these factors cause sympathetic over activity and so increases pulse rate and both SBP and DBP. $(8,9,10)$

With CPT there was decrease in pulse rate, and increase in both SBP and DBP. CPT is a simple, non-invasive, cost effective tool to find out systolic and diastolic blood pressure hyper reactors. Before time we can identify the potential hyperreactors. Who would in later life potentially suffer from hypertension in both genders. Acute exposure to cold results in vasomotor reflex to cold stimulus. Afferent pathway ascends through spinothalamic tract and the efferent descends through the corresponding spinal segments and supplies peripheral blood vessels through Sympathetic ganglia. Blood pressure increases due to pain induced reflex which results in peripheral vasoconstriction and due to increase in norepinephrine levels due to Exposure to cold. This explains rise in blood pressure due to exposure to cold. Baroreceptor reflex is stimulated which results in increase in blood pressure which decreases Pulse rate. $(4,11,12,13,14)$

Shavasana is a form of yoga which brings about complete relaxation. Practicing shavasana for 15 minutes daily there is decrease in sympathetic discharge. This decreases heart rate and force of contraction so stoke volume and cardiac output are decreased. Also, there is decrease in vasoconstriction which decreases peripheral resistance. Shavasana increases parasympathetic discharge. This decreases heart rate and force of contraction of heart. So, there is decrease in stroke volume and cardiac output. Which decreases SBP and at the same time there is peripheral vasodilatation which will decrease peripheral resistances so DBP decreases. This explains decrease in pulse rate and blood pressure after performing shavasana. So when performing shavasana for 30 days there is significant decrease in pulse rate and SBP and DBP which is of benefit in the hypertensives and can prevent cardiovascular complications in later life of the individual.

Studies in the past as per Patel and North et al and Datey et al it is seen that yoga training is known to optimize the sympathetic response to isometric HGT and it has BP lowering effect.(15,16) Also as per Ravindra et al shavasana and pranayama is beneficial in patients with premature ventricular complexes and palpitation. Studies as per Madanmohan et al have shown that, stress is known to cause HT and CAD and shavasana is very effective in controlling stress and it produces decrease in oxygen consumption and deep psychosomatic relaxation within 5 minutes of its common cement.
It is also known to improve person's ability to overcome stress as measured by CPT within about weeks' time. Twelveweek yoga. $(4,6),(17,18)$ Studies as per G. V Lathadevi et al have shown that by performing shavasana person becomes relaxed with slow rhythmic movements of the respiratory muscles and other parts of the body. As a result hypothalamus due to continuous feedback of slow rhythmic proprioceptive and exteroceptive impulses to reset it at a lower level thereby decreasing BP.(19) Studies as per A. A. Khananetal, Kavirajaudupa et al and Jyotsna Bharashankar et al have shown that there is decrease in pulse rate after pranayama and it is due to increase in vagal tone and decrease in sympathetic activity which reduces catecholamines secretion and causes vasodilatation thus improving peripheral circulation. $(20,21,22)$ As per Jyotsna Bharashankar et al and Gandhi A. both SBP and DB decrease after yoga training. And our studies are in consensus with the above-mentioned authors. $(23,24)$

\section{Recommendations}

Since CPT is a very simple, cost effective test to screen subjects who are hyper reactors to blood pressure, who would in later. Half probably suffer from hypertension and complications can be prevented by altering lifestyles. Also, it is seen that shavasana if practiced for more than one month and then continued we have observed that both pulse rate, SBP and DBP can be decreased. Which is good to prevent cardiovascular complications in later life.

\section{CONCLUSIONS}

There is a significant decrease in basal pulse rate, when compared with CPT, immediately and after performing shavasana for a period of one month, and there was significant increase in pulse rate following HGT $(\mathrm{p}<0.001)$ (table 1 and graph 1). Compared to basal, SBP and DBP both it was observed that there is significant decrease, immediately and after performing shavasana for one month and significant increase with HGT and CPT was observed $(\mathrm{p}<0.001)$ (table 1 and graph 1$)$. Also, it is seen that shavasana if practiced for more than one month and then continued then pulse rate, SBP and DBP can be decreased significantly, which is good to prevent cardiovascular complications in later life.

\section{REFERENCES}

[1] Manhas M, Gupta V, Kalsotra L. A study of cardiovascular and pulmonary responses during Cold Pressor Test (CPT) in healthy volunteers. JK Science 2011;13(3):1459.

[2] Kasturi KK. The effect of Shavasana on cardiovascular parasympathetic functions in healthy adults. National Journal of Basic Medical Sciences 2013;4(1):23-7.

[3] Shinde V, Kini R, Naik R, et al. A study on the effect of relaxation techniques and Shavasana on stress and pulse rates of medical students. Journal of Exercise Science \& Physiotherapy 2015; 11(2):123-8. 
[4] Sardessai SR, Pandarbale SS. Effect of Cold Pressor Test on blood pressure in subjects with hypertensive first degree relatives. J Evolution Med \& Dent Sci 2017;6(52):3963-6.

[5] Northcote RJ, Cooke MB. How useful are the CPT and sustained isometric exercise with radionuclide ventriculography in the evaluation of patients with coronary artery disease? Br Heart J 1987; 57(4):319-28.

[6] Hulley SB, Cummings SR, Browner WS, et al. designing an experiment: clinical trials I. Text book of Designing clinical research. $2^{\text {nd }}$ edn, Reprint. Lippincott Williams and Wilkins 2001: p. 143-93.

[7] Jain AK. Manual of practical physiology for MBBS. $5^{\text {th }}$ edn. Arya Publications 2016: p. 129-32.

[8] Jain S. Immediate effect of Shavasana on cardiac output and systemic peripheral resistance in untrained young adults. J Krishna Institute of Medical Sciences University 2016;5(1):68-73.

[9] Sandhu JS, Gill HS, Gupta V, et al. Effect of isometric handgrip training on heart rate and arterial pressure in normotensive individuals. Scholars Journal of Applied Medical Sciences 2014; 2(6A):2010-15.

[10] Jeelani M, Taklikar RH. Isometric exercise and its effect on blood pressure and heart rate; a comparative study between healthy, young and elderly males in and around Raichur city. International Journal of Scientific Study 2018;6(1):12-6.

[11] Smolander J, Aminoff T, Korhonen I, et al. Heart rate and blood pressure responses to isometric exercise in young and older men. Eur J Appl Physiol Occup Physiol 1998;77(5):439-44.

[12] Banoo H, Gangwar V, Nabi N. Effects of cold stress and the Cold Pressor Test on blood pressure and heart rate. International Archives of Biomedical and Clinical Research 2016; 2(2):65-8.

[13] Mourot L, Bouhaddi M, Regnard J. Effects of Cold Pressor Test on cardiac autonomic control in normal subjects. Physiol Res 2009; 58(1):83-91.
[14] Silverthorn DU, Michael J. Cold stress and the Cold Pressor Test. Adv Physiol Educ 2013; 37(1):93-6.

[15] Elias SO, Ajayi RE. Effect of sympathetic autonomic stress from the Cold Pressor Test on left ventricular function in young healthy adults. Physiol Rep 2019; 7(2):e13985.

[16] Datey KK, Deshmukh SN, Dalvi CP. "Shavasan": a yogic exercise in the management of hypertension. Angiology 1969;20(6):325-33.

[17] Ravindra PN, Madanmohan, Pavithran P. Effect of Pranayam (yoga breathing) and Shavasan (relaxation training) on the frequency of benign ventricular ectopics in two patients with palpitations. International J Cardiology 2006; 108(1):124-5.

[18] Madanmohan, Rai UC, Balavittal V, et al. Cardiorespiratory changes during Savitri Pranayam and Shavasan. The Yoga Review 1983; 3:25-34.

[19] Madanmohan, Udupa K, Bhavanani AB, et al, Modulation of cold pressor induced stress by Shavasan in normal adult volunteers. Indian Journal of Physiol Pharmacol 2002; 46(3):307-12.

[20] Lathadevi GV, UmaMaheshwari T, Nagashree R. Modulation of cardiovascular response after Ujjayi pranayama and Shavasana training in normal human volunteers. Journal of Clinical and Diagnostic Research 2012; 6(4):571-3.

[21] Khanam AA, Sachdeva U, Guleria R, et al. Study of pulmonary and autonomic functions of asthma patients after yoga training. Indian Journal of Physiol Pharmacol 1996; 40(4):318-24.

[22] Udupa K, Madanmohan, Bhavanani AB, et al. Effect of Pranayama training on cardiac function in normal young volunteers. Indian Journal of Physiol Pharmacol 2003; 47(1):27-33.

[23] Jyotsana RB, Rajay NB, Vijaykumar ND, et al. Effect of yoga on cardiovascular system in subjects above 40 years. Indian Journal of Physiol Pharmacol 2003; 47(2):202-6.

[24] Gandhi A, Kumar M. Comparative study of effect of pranayama and meditation practice on autonomic functions in young healthy females. Indian Journal of Physiol Pharmacol 2006; 52(5):183. 